\title{
Anti-inflammatory Effects of Metformin on Neuro-inflammation and NLRP3 Inflammasome Activation in BV-2 Microglial Cells
}

\author{
Ji-Sun Ha ${ }^{1, *}$, Yun-Seon Yeom ${ }^{1, * *}$, Ju-Hun Jang ${ }^{1, * *}$, Yong-Hee Kim ${ }^{1, * *}$, \\ Ji In Im ${ }^{1, * *}$, In Sik Kim ${ }^{2, * * *}$ and Seung-Ju Yang ${ }^{1, \dagger ; * * *}$ \\ ${ }^{I}$ Department of Biomedical Laboratory Science, Konyang University, Daejeon 35365, Korea \\ ${ }^{2}$ Department of Biomedical Laboratory Science, School of Medicine, Eulji University, Daejeon 34824, Korea
}

\begin{abstract}
Metformin is a drug used for the treatment of diabetes and is associated with anti-inflammatory reaction, but the underlying mechanism is unclear. In this study, we investigated the effect of metformin on the inflammatory response in BV-2 microglial cells induced by lipopolysaccharide (LPS) and S100 calcium-binding protein A8 (S100A8). The results revealed that metformin significantly attenuated several inflammatory responses in BV-2 microglial cells, including the secretion of pro-inflammatory cytokines, such as tumor necrosis factor- $\alpha$ and interleukin (IL)-6, involved in the activation of Beclin-1, a crucial regulator of autophagy. In addition, metformin inhibited the LPS-induced phosphorylation of ERK. Metformin also suppressed the activation of NOD-like receptor pyrin domain containing 3 inflammasomes composed of NLRP3, caspase-1, and apoptosis-associated speck like protein containing a caspase recruitment domain, which are involved in the innate immune response. Notably, metformin decreased the secretion of S100A8-induced IL-6 production. These findings suggest that metformin alleviates the neuroinflammatory response via autophagy activation.
\end{abstract}

Key Words: Autophagy, Metformin, Microglia, NLRP3 inflammasome

\section{INTRODUCTION}

Microglial cells as a resident phagocyte in the central nervous system are essential for the neuroinflammatory response. Once activated by danger-associated molecular patterns (DAMPs) such as S100A8, S100A9, and beta( $\beta$ )amyloid or pathogen-associated molecular patterns (PAMPs) such as ATP, interferon $\gamma$, and lipopolysaccharides (LPS), microglial cells initiate an innate immune response (Heneka et al., 2015). It has been reported that activated BV-2 microglial cells secrete pro-inflammatory cytokines, such as tumor necrosis factor (TNF)- $\alpha$ and interleukin (IL)-6 (Cunha et al., 2016). Therefore, regulating the activation of microglia cells might have anti-inflammatory effects.

Furthermore, the nucleotide binding and oligomerization domain-like receptor containing a pyrin domain (NLRP3) inflammasomes are activated by the nuclear factor- $\mathrm{KB}$ (NF$\kappa B)$ and mitogen-activated protein kinase (MAPK) signaling pathways (Bauernfeind et al., 2009). Although NLRP3 inflammasome consists of NLRP3, the apoptosis-associated speck-like protein containing a C-terminal caspase recruitment domain (ASC) and pro-caspase-1 activate both procaspase- 1 and IL-1 $\beta$ to regulate the immune response (Jo et al., 2016).

It has been reported that autophagy regulates inflam-

Received: February 28, 2019/ Revised: March 21, 2019 / Accepted: March 22, 2019

*Gaduate student, ${ }^{* *}$ Undergraduate student, ${ }^{* * *}$ Professor.

${ }^{\dagger}$ Corresponding author: Seung-Ju Yang. Department of Biomedical Laboratory Science, Konyang University, Daejeon 35365, Korea.

Tel: +82-10-7373-5922, Fax: +82-10-7373-5922, e-mail: sjyang@konyang.ac.kr

(OThe Korean Society for Biomedical Laboratory Sciences. All rights reserved.

(9) This is an Open Access article distributed under the terms of the Creative Commons Attribution Non-Commercial License (http://creativecommons.org/licenses/by-nc/3.0/) which permits unrestricted non-commercial use, distribution, and reproduction in any medium, provided the original work is properly cited. 
matory responses via the downregulation of NF- $\kappa \mathrm{B}$ and pro-inflammatory cytokines (Levine et al., 2011; Kim et al., 2014). Moreover, autophagy also inhibits the activation of inflammasome structures, and thus contributes to the dampening of pro-inflammatory response (Netea-Maier et al., 2015; Qian et al., 2017b). However, the process by which autophagy negatively regulates NLRP3 inflammasome is unknown.

Metformin activates AMP-activated protein kinase (AMPK), one of the steps in autophagy and an enzyme important for insulin activation, and is used for the treatment for type 2 diabetes. In fact, studies have reported the beneficial effects of metformin in various disorders, including morphine analgesia (Pan et al., 2016) and prostate cancer (Whitburn et al., 2017). However, most studies on such effects of metformin have not discussed microglia activation, specifically through NLRP3 inflammasome mediation and DAMP-stimulated inflammation. In this study, we aimed to investigate the anti-inflammatory effects of metformin in relation to its regulatory role on inflammatory responses and NLRP3 inflammasome activation via autophagy activation.

\section{MATERIALS AND METHODS}

\section{Materials}

Both metformin and LPS were obtained from SigmaAldrich (St. Louis, MO, USA). Dulbecco's modified Eagle's medium (DMEM) and phosphate-buffered saline (PBS) were purchased from Hyclone (Logan, UT, USA). Penicillin $(100 \mathrm{U} / \mathrm{mL}) /$ streptomycin $(100 \mu \mathrm{g} / \mathrm{mL})$ was purchased from Gibco (Life Technologies Inc., Gaithersburg, MD, USA), and heat-inactivated fetal bovine serum (FBS) was obtained from Pan Biotech (Aidenbach, Germany). The S100A8 protein was synthesized and purified as previously described (Kim et al., 2015). Both TNF- $\alpha$ and IL-6 were quantitatively measured by an enzyme-linked immunosorbent assay (ELISA) using the mouse TNF- $\alpha$ and IL-6 DuoSet ELISA kit (R\&D systems, Minneapolis, MN, USA), according to the manufacturer's instructions. The following antibodies were used for western blotting: anti-Beclin-1, anti-ERK, anti-pERK, and anti-NLRP3 from Cell Signaling Technology (Beverly, MA, USA); anti-caspase-1 (p20) and anti-ASC from AdipoGen Life Science (USA); and anti-JNK, antip-JNK, and anti- $\beta$-actin from Santa Cruz Biotechnology (Santa Cruz, CA, USA).

\section{Cell culture}

BV-2 microglial cell line was obtained from the Dr. SungWoo Cho in Department of Biochemistry and Molecular Biology, University of Ulsan College of Medicine (Seoul, South Korea) and was maintained in DMEM supplemented with penicillin $(100 \mathrm{U} / \mathrm{mL})$, streptomycin $(100 \mu \mathrm{g} / \mathrm{mL})$, and $10 \% \mathrm{FBS}$ at $37^{\circ} \mathrm{C}$. The cells were incubated in a humidified atmosphere containing $5 \% \mathrm{CO}_{2}$.

\section{MTT assay}

BV-2 microglial cells were seeded in a 96-well plate $(1 \times$ $10^{4}$ cells/well) and cultured overnight. Subsequently, they were incubated with metformin $(1,2,4,8$, and $10 \mathrm{mM})$. After incubation for $24 \mathrm{~h}$, the cells were assayed for cell viability by the addition of Ez-Cytox reagent ( $20 \mu \mathrm{L} /$ well) and further incubated for $1 \mathrm{~h}$ at $37^{\circ} \mathrm{C}$. Thereafter, the absorbance of sample in the 96-well plate was measured using an ELISA microplate reader (Molecular Device, Sunnyvale, CA, USA) at $450 \mathrm{~nm}$.

\section{Enzyme-linked immunosorbent assay}

BV-2 microglial cells were seeded in a 6 -well plate $(5 \times$ $10^{5}$ cells/well) and incubated with metformin $(2,4$, and 6 $\mathrm{mM})$ for $20 \mathrm{~h}$, followed by treatment with LPS $(10 \mathrm{ng} / \mathrm{mL})$ or S100A8 $(10 \mu \mathrm{g} / \mathrm{mL})$. After incubation for $4 \mathrm{~h}$, cell-free supernatants were collected and the level of both TNF- $\alpha$ and IL-6 was measured in the extracellular medium using the mouse TNF- $\alpha$ and IL-6 DuoSet ELISA kit, according to the manufacturer's instructions. The absorbance of solution was measured at $450 \mathrm{~nm}$ using a ELISA microplate reader. All assays were performed as three independent experiments. The level of both TNF- $\alpha$ and IL- 6 was calculated employing the standard value obtained from a linear regression equation.

\section{Western blot analysis}

Following the treatment with both LPS $(10 \mathrm{ng} / \mathrm{mL})$ or S100A8 $(10 \mu \mathrm{g} / \mathrm{mL})$ and metformin $(2 \mathrm{mM})$ at specific times, BV-2 microglial cell pellets were lysed using either 
the cytosolic extraction or RIPA buffer. Thereafter, protein samples $(30 \mu \mathrm{g} /$ lane $)$ were separated by sodium dodecyl sulfate (SDS)-polyacrylamide gel electrophoresis on 10 $12 \%$ SDS gels. The proteins were transferred onto a nitrocellulose membrane, and then the membrane was incubated overnight at $4{ }^{\circ} \mathrm{C}$ with the primary antibody, followed by incubation for $1 \mathrm{~h}$ at room temperature with either the antirabbit IgG HRP or the anti-mouse IgG HRP secondary antibodies. The protein bands on the membrane were developed using an enhanced chemiluminescence detection system (Vilber Lourmat, Marne-la-Vallee, France).

\section{Statistical analyses}

Data are presented as mean \pm standard error and are representative of three independent experiments. SPSS statistical

A

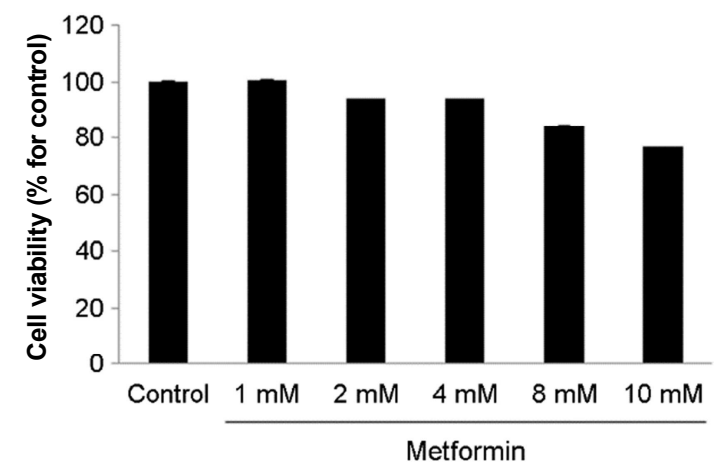

C

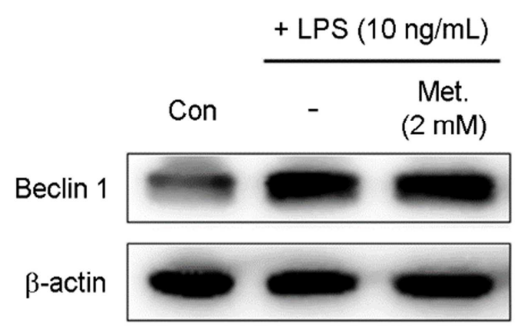

software package (Version 18.0, Chicago, IL, USA) was used for the analysis of variance (ANOVA), as appropriate. Additionally, individual differences among each group were compared through one-way ANOVA, followed by Scheffe and Dunnett T3 methods. The results with $P<0.05$ were considered statistically significant.

\section{RESULTS}

Metformin increased autophagy protein level in LPSinduced BV-2 microglial cells

The cytotoxicity of metformin was evaluated prior to the analysis of autophagy activation in BV-2 cells. Metformin did not exhibit cytotoxicity at low concentrations (Fig. 1A). The result suggests that metformin did not affect the viability

B

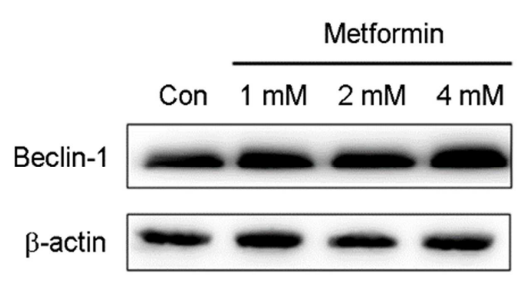

D

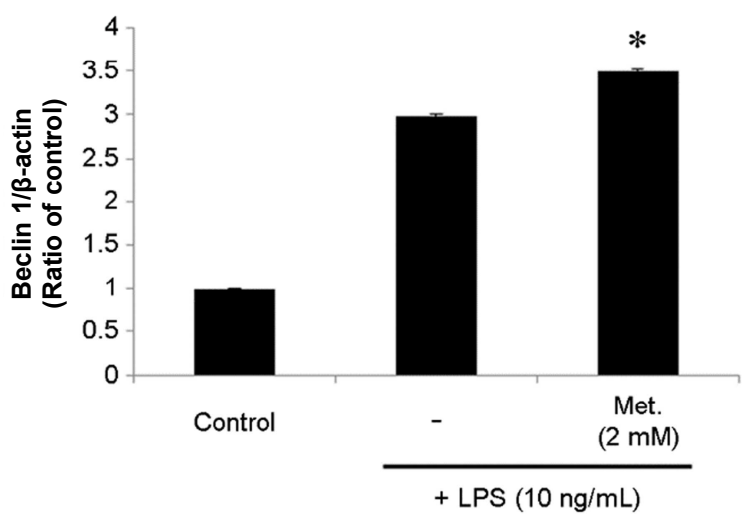

Fig. 1. Metformin did not markedly affect cell viabilities and autophagy activation in BV-2 microglial cells. (A) Effects of Metformin on cell viability. BV-2 microglial cells were incubated with indicated concentrations of Metformin for $24 \mathrm{~h}$. Cell viabilities were assessed by the MTT assay. (B) BV-2 microglial cells were incubated with indicated concentrations of Metformin for $24 \mathrm{~h}$. Metformin (1, 2, and $4 \mathrm{mM})$ increased expression of Beclin-1. (C) BV-2 microglial cells were incubated with $2 \mathrm{mM}$ of Metformin for $20 \mathrm{~h}$ followed by treatment with LPS (10 ng/mL) for $4 \mathrm{~h}$. Beclin-1 was confirmed by western blotting. (D) The relative ratio of Beclin- $1 / \beta$-actin. Data from three independent experiments are presented as the means \pm S.D. $* \leq 0.05$, $* *<0.01, * * *<0.001$ are related with Metformin treated cells. 
A

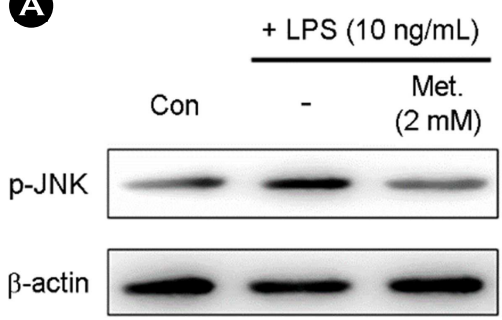

B

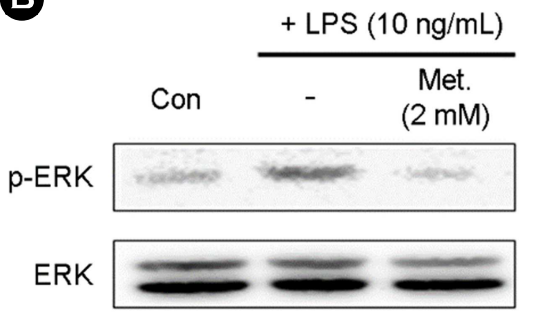

C

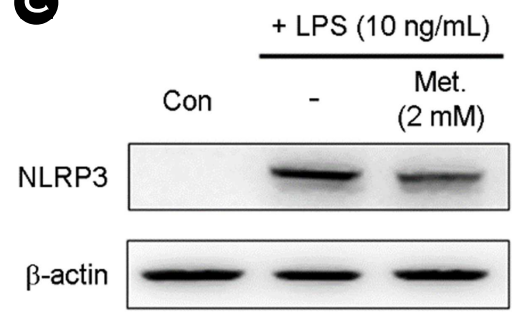

D

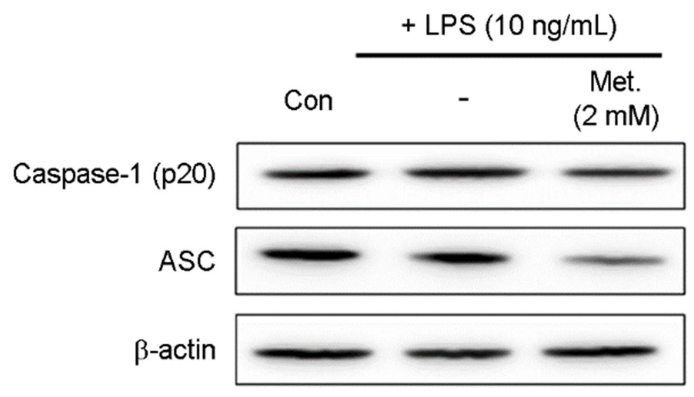

E

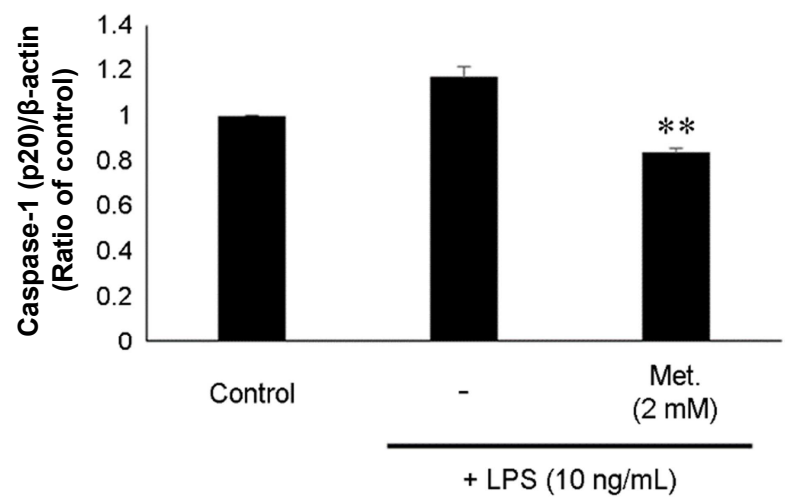

Fig. 2. Effects of Metformin on JNK, ERK, NLRP3 inflammasome expression in LPS-induced BV-2 microglial cells. BV-2 microglial cells were incubated with indicated concentrations of Metformin for $20 \mathrm{~h}$ followed by treatment with LPS $(10 \mathrm{ng} / \mathrm{mL})$ for $4 \mathrm{~h}$. BV-2 microglial cells were lysed to whole lysates. The expression of (A) p-JNK, (B) p-ERK, (C) NLRP3, (D) caspase-1(p20), and ASC was examined by Western blot. $\beta$-actin was used as an internal control. (E) The relative ratio of caspase-1 (p20)/ $\beta$-actin. Data from three independent experiments are presented as the means \pm S.D. $* \leq 0.05, * *<0.01, * * *<0.001$ are related with Metformin treated cells.

of BV-2 cells. The expression of autophagy active protein, Beclin-1, was upregulated by metformin in BV-2 cells (Fig 1B). In addition, the expression of Beclin-1 was significantly increased in metformin and LPS-treated BV-2 cells compared with that in LPS alone-induced BV-2 cells (Fig. 1C and D). These results suggest that metformin induces autophagy without affecting cell viability.

Metformin inhibited both the phosphorylation of JNK and ERK and the activation of NLRP3 inflammasome in LPS-treated BV-2 cells

We examined the phosphorylation of JNK to confirm the anti-inflammatory effects of metformin. As shown in Fig. 2A, LPS induced the phosphorylation of JNK, whereas the metformin treatment blocked the phosphorylation.

It has been reported that the activation of MAPKs, such as ERK, mediates the activation of NLRP3 inflammasomes in microglia (Huang et al., 2018). Following the identification of inhibition of LPS-induced phosphorylation of ERK by metformin (Fig. 2B), we evaluated whether metformin could prevent the activation of NLRP3 inflammasome in LPStreated BV-2 cells. Western blot analysis demonstrated that the expression of NLRP3, active caspase-1, and ASC was increased in response to LPS stimulation, and the treatment with metformin significantly downregulated LPS-induced protein expression (Fig. 2C and D). These results indicate that metformin reduced the immune response and decreased NLRP3 inflammasome in LPS-stimulated BV-2 cells.

\section{Effects of metformin on the secretion of pro-inflammatory} cytokines in LPS-induced BV-2 cells

The protective effect of metformin on pro-inflammatory cytokines was further investigated using the ELISA. As shown in Fig. 3A and B, both TNF- $\alpha$ and IL-6 levels were 
A

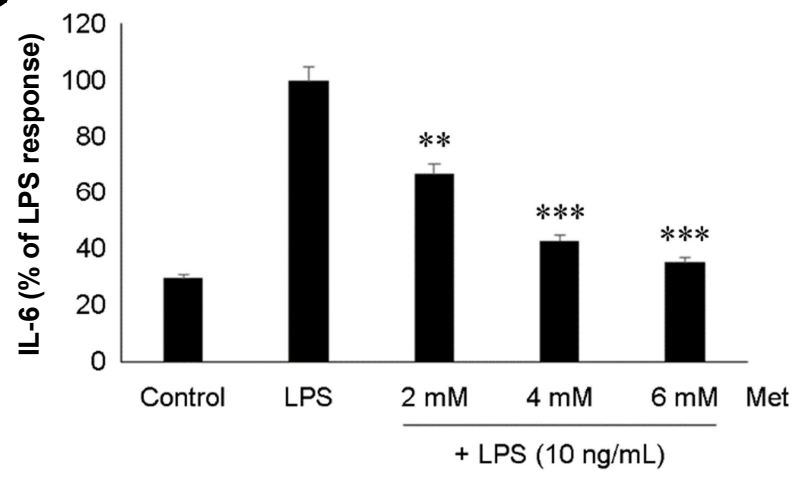

B

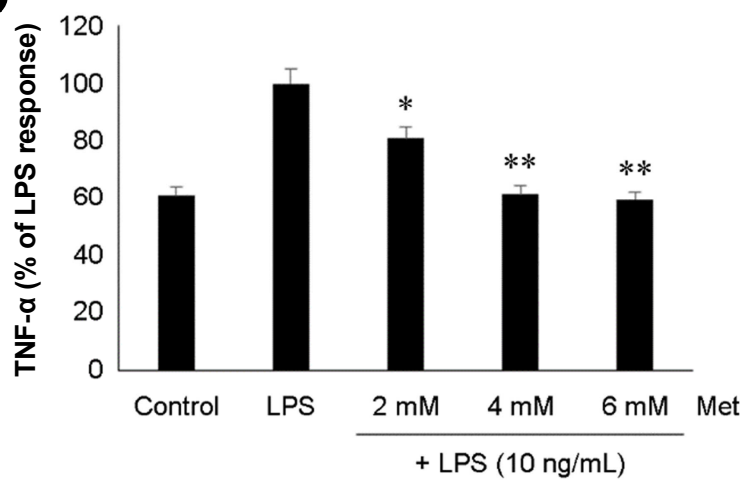

Fig. 3. Metformin prohibits the expression of pro-inflammatory cytokine in LPS treated BV-2 microglial cells. (A and B) BV-2 microglial cells were treated with indicated concentrations of Metformin for $20 \mathrm{~h}$ followed by treatment with LPS (10 ng/mL) for $4 \mathrm{~h}$ Cell-free conditioned culture medium collected and were analyzed by ELISA for IL- 6 , TNF- $\alpha$. Data from three independent experiments are presented as the means \pm S.D. $* \leq 0.05, * *<0.01, * * *<0.001$ are related with LPS-induced cells and Metformin treated cells.

A

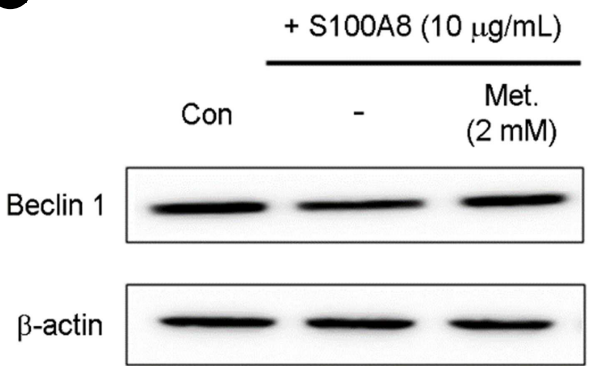

C

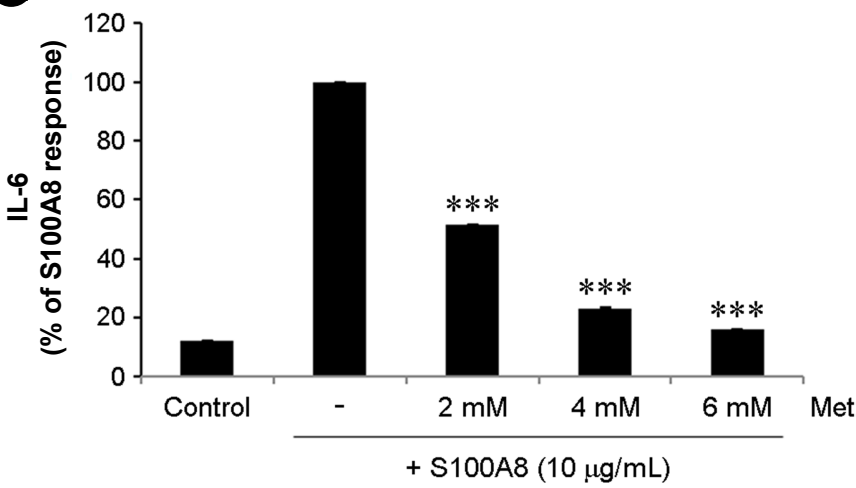

B

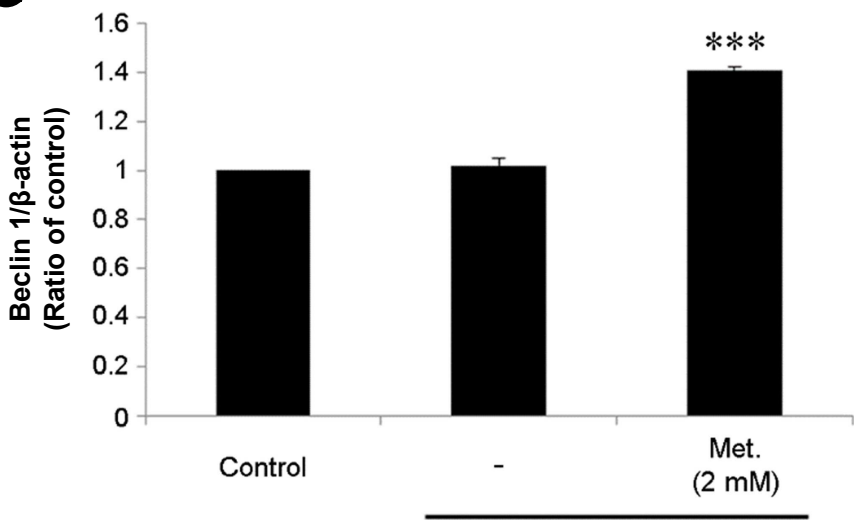

$+\mathrm{S} 100 \mathrm{~A} 8(10 \mu \mathrm{g} / \mathrm{mL})$

Fig. 4. Metformin has anti-inflammation effect in S100A8-stimulated BV-2 microglial cells. BV-2 microglial cells were incubated with $2 \mathrm{mM}$ Metformin for $20 \mathrm{~h}$ followed by treatment with S100A8 $(10 \mu \mathrm{g} / \mathrm{mL})$ for $4 \mathrm{~h}$. (A) Metformin (2 mM) induced the Beclin-1 in BV-2 microglial cells. (B) The relative ratio of Beclin-1/3-actin. (C) Level of IL-6 in the culture media were determined by ELISA. Data from three independent experiments are presented as the means \pm S.D. $* \leq 0.05, * *<0.01$, $* * *<0.001$ are related with S100A8-stimulated cells and Metformin treated cells. found to be increased in LPS-treated BV-2 cells. However, their secretion decreased in a dose-dependent manner with metformin treatment. These data suggested that metformin could suppress the secretion of pro-inflammatory cytokines induced by LPS.
Metformin attenuated the secretion of pro-inflammatory cytokines induced by S100A8 by activating Beclin-1 in BV-2 cells

S100A8 has been reported to upregulate inflammatory 
response (Wang et al., 2018). Thus, we examined whether metformin regulates the secretion of pro-inflammatory cytokines via the activation of autophagy. The cells were incubated with metformin $(2 \mathrm{mM})$, with or without S100A8 $(10 \mu \mathrm{g} / \mathrm{mL})$, for $24 \mathrm{~h}$. Unlike that in LPS-stimulated BV-2 cells, the activity of Beclin-1 decreased in BV-2 cells treated with S100A8. However, metformin activated Beclin-1 in S100A8-induced BV-2 cells (Fig. 4A). BV-2 cells were incubated with the indicated concentration of both metformin and S100A8. Although S100A8 markedly increased the IL-6 level, it was inhibited by metformin in a dose-dependent manner (Fig. 4B). These results further demonstrated that metformin can inhibit S100A8-induced pro-inflammatory cytokine secretion in BV-2 cells.

\section{DISCUSSION}

Recent studies have suggested that metformin might have neuroprotective effect in several neurologic diseases such as Alzheimer's disease (Chen et al., 2009) and Parkinson's disease (Kuan et al., 2017). Furthermore, activated microglial cells release pro-inflammatory cytokines such as TNF- $\alpha$ and IL-6 in chronic neurodegenerative diseases (Hanisch, 2002). The present study results indicated the effects of metformin on the activation of microglial cells following LPS or S100A8 treatment, as evidenced by a significant decrease in pro-inflammatory cytokine levels after metformin treatment.

In addition, neurodegenerative diseases might be associated with the activation of NLRP3 inflammasomes (Song et al., 2017). NLRP3 inflammasomes are an intracellular protein complex sensor that recognize PAMPs and DAMPs. They regulate the immune response in microglial cells by activating both pro-caspase-1 and IL-1 $\beta$ (Abderrazak et al., 2015). However, the effect of metformin on NLRP3 inflammasome is unknown.

In the present study, we confirmed the effect of metformin on NLRP3 inflammasome activation. The results indicated that metformin considerably reduced the expression of NLRP3, active caspase-1, and ASC. Studies have suggested that NLRP3 inflammasome activates MAPK signaling, a well-known inflammatory response (Bauernfeind et al., 2009; Fan et al., 2017). Moreover, our findings suggested the inhibition of MAPK signaling molecules, such as p-JNK and p-ERK, in metformin-treated BV-2 cells.

Recent studies have suggested that the activation of autophagy inhibits inflammation (Netea-Maier et al., 2015; Qian et al., 2017a). Therefore, we thought that autophagy activation, which is characteristic of metformin, results in anti-inflammation effect. Unexpectedly, the expression of autophagy protein Beclin-1 was increased in metformintreated BV-2 cells stimulated with LPS and S100A8.

In summary, we demonstrated that metformin reduces the activation of NLRP3 inflammasomes, inhibits the proinflammatory and MAPK signaling pathways in LPS-induced BV-2 cells, and reduces the secretion of IL-6 in S100A8stimulated BV-2 cells by Beclin-1 activation. Although the mechanism that regulates the activation of NLRP3 inflammasomes has not been clearly elucidated, our study proposes that metformin might be a candidate drug for the treatment of neuroinflammation.

\section{ACKNOWLEDGEMENT}

This research was supported by the Basic Science Research Program through the National Research Foundation of Korea (NRF) funded by the Ministry of Education (2018R1D1A3A03000692).

\section{CONFLICT OF INTEREST}

No potential conflict of interest relevant to this article was reported.

\section{REFERENCES}

Abderrazak A, Syrovets T, Couchie D, El Hadri K, Friguet B, Simmet T, Rouis M. Nlrp3 inflammasome: From a danger signal sensor to a regulatory node of oxidative stress and inflammatory diseases. Redox Biol. 2015. 4: 296-307.

Bauernfeind F, Horvath G, Stutz A, Alnemri ES, MacDonald K, Speert D, Fernandes-Alnemri T, Wu J, Monks BG, Fitzgerald KA, Hornung V, Latz E. Nf-kb activating pattern recognition and cytokine receptors license nlrp3 inflammasome activation by regulating nlrp3 expression. J Immunol. 2009. 183: 787 $-791$.

Chen Y, Zhou K, Wang R, Liu Y, Kwak YD, Ma T, Thompson RC, Zhao Y, Smith L, Gasparini L, Luo Z, Xu H, Liao FF. Antidia- 
betic drug metformin (glucophager) increases biogenesis of alzheimer's amyloid peptides via up-regulating bace1 transcription. Proceedings of the National Academy of Sciences. 2009. 106: 3907-3912.

Cunha C, Gomes C, Vaz AR, Brites D. Exploring new inflammatory biomarkers and pathways during lps-induced $\mathrm{m} 1$ polarization. Mediators of Inflammation. 2016. 2016: 1-17.

Fan HH, Zhu LB, Li T, Zhu H, Wang YN, Ren XL, Hu BL, Huang $\mathrm{CP}$, Zhu JH, Zhang X. Hyperoside inhibits lipopolysaccharideinduced inflammatory responses in microglial cells via p38 and nfkappab pathways. Int Immunopharmacol. 2017. 50: 14 -21 .

Hanisch UK. Microglia as a source and target of cytokines. Glia. 2002. 40: 140-155.

Heneka MT, Carson MJ, Khoury JE, Landreth GE, Brosseron F, Feinstein DL, Jacobs AH, Wyss-Coray T, Vitorica J, Ransohoff RM, Herrup K, Frautschy SA, Finsen B, Brown GC, Verkhratsky A, Yamanaka K, Koistinaho J, Latz E, Halle A, Petzold GC, et al. Neuroinflammation in alzheimer's disease. The Lancet Neurology. 2015. 14: 388-405.

Huang MY, Tu CE, Wang SC, Hung YL, Su CC, Fang SH, Chen CS, Liu PL, Cheng WC, Huang YW, Li CY. Corylin inhibits lps-induced inflammatory response and attenuates the activation of nlrp3 inflammasome in microglia. BMC Complement Altern Med. 2018. 18.

Jo EK, Kim JK, Shin DM, Sasakawa C. Molecular mechanisms regulating nlrp3 inflammasome activation. Cell Mol Immunol. 2016. 13: 148-159.

Kim DH, Choi E, Lee JS, Lee NR, Baek SY, Gu A, Kim IS. House dust mite allergen regulates constitutive apoptosis of normal and asthmatic neutrophils via toll-like receptor 4. PLoS One. 2015. 10.

Kim J, Kwak HJ, Cha J-Y, Jeong Y-S, Rhee SD, Kim KR, Cheon HG. Metformin suppresses lipopolysaccharide (lps)-induced inflammatory response in murine macrophages via activating transcription factor-3 (atf-3) induction. Journal of Biological Chemistry. 2014. 289: 23246-23255.

Kuan YC, Huang KW, Lin CL, Hu CJ, Kao CH. Effects of metformin exposure on neurodegenerative diseases in elderly patients with type 2 diabetes mellitus. Prog Neuropsychopharmacol Biol Psychiatry. 2017. 79: 77-83.

Levine B, Mizushima N, Virgin HW. Autophagy in immunity and inflammation. Nature. 2011. 469: 323-335.

Netea-Maier RT, Plantinga TS, van de Veerdonk FL, Smit JW, Netea MG. Modulation of inflammation by autophagy: Consequences for human disease. Autophagy. 2015. 12: 245-260.

Pan Y, Sun X, Jiang L, Hu L, Kong H, Han Y, Qian C, Song C, Qian Y, Liu W. Metformin reduces morphine tolerance by inhibiting microglial-mediated neuroinflammation. Journal of Neuroinflammation. 2016. 13.

Qian M, Fang X, Wang X. Autophagy and inflammation. Clinical and Translational Medicine. 2017a. 6.

Qian S, Fan J, Billiar TR, Scott MJ. Inflammasome and autophagy regulation: A two-way street. Mol Med. 2017b. 23: 188-195.

Song L, Pei L, Yao S, Wu Y, Shang Y. Nlrp3 inflammasome in neurological diseases, from functions to therapies. Front Cell Neurosci. 2017. 11: 63.

Wang S, Song R, Wang Z, Jing Z, Wang S, Ma J. S100a8/a9 in inflammation. Frontiers in Immunology. 2018. 9.

Whitburn J, Edwards CM, Sooriakumaran P. Metformin and prostate cancer: A new role for an old drug. Curr Urol Rep. 2017. 18.

https://doi.org/10.15616/BSL.2019.25.1.92

Cite this article as: Ha JS, Yeom YS, Jang JH, Kim YH, Im JI, Kim IS, Yang SJ. Anti-inflammatory Effects of Metformin on Neuro-inflammation and NLRP3 Inflammasome Activation in BV-2 Microglial Cells. Biomedical Science Letters. 2019. 25: 92-98. 